Научная статья

УДК 37.014 .3

DOI: $10.18101 / 1994-0866-2020-4-16-23$

\title{
ГУМАНИЗАЦИЯ ОБРАЗОВАНИЯ В СУДЬБЕ ЧЕЛОВЕЧЕСТВА: НЕВОЗМОЖНОСТЬ ИЛИ ДАР ХХ ВЕКА?
}

\author{
(С Сандакова Людмила Гармаевна \\ доктор философских наук, доцент, \\ Алтайский государственный институт культуры \\ Россия, 656055, г. Барнаул, ул. им. А. Юрина, 277 \\ aivt@list.ru \\ (С) Ильин Роман Валерьевич \\ аспирант, \\ Алтайский государственный институт культуры \\ Россия, 656055, г. Барнаул, ул. им. А. Юрина, 277 \\ aivt@list.ru
} зав. отделом организации научно-исследовательской деятельности

\begin{abstract}
Аннотация. В статье отражены результаты анализа исторического развития человечества. По мнению авторов, это борьба двух начал: гуманистического и технократического. Она берет начало в осевое время и длится до сих пор... В XX в. противостояние между ними устранено через диалектическое единство внешнего и внутреннего; гуманистического и технологического. В нынешнем веке А. П. Назаретян разрешил это противоречие, найдя зависимость между ними, и выразил это в законе техно-гуманитарного баланса. На основе соответствующей модели и вводимых им регуляторов он проводит анализ мегатрендов и механизмов эволюции, проектирует нелинейное будущее человечества, устремленного к балансу между гуманистической культурой и биологической природой человека. Авторы данной статьи используют модель А. П. Назаретяна для экспликации гуманистического образования - модель развивающего образования XX в. как великого дара выдающихся советских, российских ученых и неизбежности введения его в массовую образовательную практику современного образования.

Ключевые слова: историческое развитие; гуманистическое образование; технократическое развитие человечества; развивающее обучение; гуманизация образования; закон (модель) техно-гуманитарного образования; агрессия; насилие; мегатренды; механизмы эволюции; проектирование; образовательная практика; массовое образование; массовая профессия; гуманистическая культура и биологическая природа человека.
\end{abstract}

\section{Для цитирования}

Сандакова Л. Г., Ильин Р. В. Гуманизация образования в судьбе человечества: невозможность или дар XX века // Вестник Бурятского государственного университета. Философия. 2020. Вып. 4. С. 16-23.

В истории человечества исследовано, пожалуй, уже все, начиная с Геродота до современных исследователей, разработано огромное количество концепций, гипотез и теорий, объясняющих предпосылки, причины, ход и результат тех или 
Л. Г. Сандакова, Р. В. Ильин. Гуманизация образования в судьбе человечества: невозможность или дар XX века?

иных исторических событий, эпохальных и не очень, а также эксплицирующих подходы авторов к развитию человечества. Анализ истории человечества, его выживания и сохранения показывает, что люди создавали свою цивилизацию, культуру и системы образования под влиянием внешних и внутренних факторов, как ответ на вызовы времени и внутренние потребности.

Среди множества трудов историков, философов, психологов и даже математиков, изданных в последние годы, наибольший интерес вызывает монография А. П. Назаретяна [1, с. 105], в которой подробно обоснован вывод о том, что сознание, успевшее сделаться планетарным фактором, способно перерасти в фактор космологический (по В. И. Вернадскому). Автор считает, что решающим препятствием для этого могут стать не пределы управляемости материальноэнергетического мира, а неготовность разума совладать с инструментальным могуществом человечества. Также наибольший интерес вызывает его модель техногуманитарного баланса, в которой впервые в отечественной и зарубежной литературе противоречащие тенденции развития человечества (обеспечение техникотехнологического могущества государств и сохранение человеческого, гуманистического начала в общественных отношениях) рассматриваются как взаимосвязанные и взаимозависимые процессы. А. П. Назаретян так формулирует закон техно-гуманитарного баланса как обобщенной зависимости: «чем выше мощь производственных и боевых технологий, тем более совершенные средства культурной регуляции необходимы для сохранения социума... Жизнеспособность социальной системы определяется соотношением внешней и внутренней устойчивости, которые по-разному зависят от технологического потенциала. Первая $(E x-$ sternal Sustainability, Se) выражает способность социальной системы противостоять спонтанным колебаниям природной и геополитической среды. Вторая (Internal Sustainability, Si) - способность избегать разрушительных последствий собственной деятельности... внешняя устойчивость является положительной функцией технологического потенциала (T): $\mathrm{Se}=\mathrm{g}(\mathrm{T})$. Связь между технологическим потенциалом и внутренней устойчивостью тоньше и носит, скорее, отрицательный характер; для ее формального представления необходима еще одна переменная - качество регуляторных механизмов культуры (R). В итоге мы получаем основную формулу техно-гуманитарного баланса: $\mathrm{Si}=\mathrm{f}_{1}(\mathrm{R}) / \mathrm{f}_{2}(\mathrm{~T}), \ldots \mathrm{T}>0$, поскольку при нулевой технологии мы имеем дело уже не с социумом, а со стадом, где действуют иные биологические и зоопсихологические законы... Наконец, рост величины в знаменателе повышает вероятность антропогенных кризисов, если не компенсируется ростом показателя в числителе. В этом случае снижается «дуракоустойчивость» (fool proof) общества. Социум, бывший прежде «взрослым», становится инфантильным, более зависимым от массовых настроений, решения авторитетных лидеров и т. д.» [1, с. 106]. Как следует из приведенных выше формул, "растущий технологический потенциал делает социальную систему менее зависимой от состояний и колебаний внешней среды, но вместе с тем более чувствительной к колебаниям массового и индивидуального сознания» [1, c. 106].

А. П. Назаретян объясняет, что рост технологического могущества развитых обществ позволяет быстрее справляться с последствиями катастроф и катаклиз- 
мов, т. е. с внешними угрозами технологически развитая социальная система легче и эффективнее, нежели менее развитые общества. С другой стороны, такие общества становятся неустойчивыми к внутренним проблемам и зависят от колебаний общественного сознания, хотя и им в технократических обществах научились манипулировать.

Как же формируется общественное сознание и почему становится так легко манипулировать им в современном мире развитых телекоммуникационных и информационных технологий? Это очень сложный вопрос, на его решение влияет множество факторов, среди которых важнейшим является образование, поскольку основным его результатом является сознание и мышление человека, главным образом научного, и чем больше оно развито, тем больший вклад им вносится в общественное сознание. Развитие индивидуального сознания и мышления зависит в большей степени от желания, потребности самого субъекта образовательной деятельности. К числу несубъективных факторов, играющих в этом процессе важную роль, относятся содержание образования и педагогическое воздействие. Из множества индивидуальных сознаний и результатов их деятельности складывается, но не равно их сумме, а в разы ее превышает, общественное сознание. Приведем определения феномена «общественное сознание»: в широком смысле слова «общественное сознание - это духовная жизнь общества в совокупности чувств, настроений, взглядов, идей, теорий, отражающих общественное бытие и влияющих на него. Отображение в духовной деятельности людей интересов, представлений различных социальных групп, классов, наций, общества в целом» ${ }^{1}$. В узком смысле «общественное сознание - совокупность психологических свойств, присущих обществу, рассматриваемому как самостоятельная целостность, система, не сводимая к сумме составляющих его индивидов» ${ }^{2}$.

Существует несколько подходов к определению общественного сознания: диалектико-материалистический; объективно-идеалистический; субъективноидеалистический. Субъектом общественного сознания является не индивид, а социум, общество. Формы общественного сознания общеизвестны (нравственное, эстетическое, религиозное, правовое, политическое, философское, научное, экологическое, экономическое и т. д.) и отражают различные сферы жизнедеятельности общества, но идеологии уделяется особое внимание. Идеология - это система идей и теорий, ценностей и норм, идеалов и директив действия, которая способствует фиксации или устранению существующих общественных отношений. Именно идеология определяет социальное поведение субъекта общественных отношений (индивид, страта, общество и т. п.), поскольку она является главным инструментом манипуляции массового сознания.

Искусство, философия, религия и наука - основные формы духовной культуры, которые аккумулируют опыт человечества, накопленный за миллионы лет существования. Главной целью образования с древних времен была передача накопленного опыта подрастающему поколению. Кроме того, считалось, что

${ }^{1}$ URL: WebStarStudio.com`marketing/theor/fil//vopr1.htm (дата обращения: 03.11.2020).

${ }^{2}$ Там же. 
Л. Г. Сандакова, Р. В. Ильин. Гуманизация образования в судьбе человечества: невозможность или дар XX века?

детскую природу можно было «укротить» только насилием. Как говорилось: вбивать культуру кулаком или через длительное сидение за столом, выполняя рутинную домашнюю работу по закреплению знаний, полученных в образовательном учреждении. В большинстве этнопедагогических систем образование мыслилось как насилие, и другие варианты не рассматривались. Почему насилие приходило на ум педагогам разных эпох и народов? Вся всемирная история построена на насилии, в основе которой лежит присущая всем видам живых существ агрессия. Она делится на два вида: межвидовую и внутривидовую. Межвидовая агрессия выражается в формуле «свой - чужой» и используется в том случае, когда в племени, сообществе или страте возникают настроения, которые могли привести к конфликтам, свержению власти или переделу сфер влияния. Внутривидовая агрессия приводит к неустойчивости и распаду системы, например, послереволюционные гражданские войны США, Франции, России и др. Чтобы не возникали подобные деструктивные ситуации, политики научились «сублимировать» разрушительную силу внутривидовой агрессии в межвидовую: объявляют внешним врагом какую-нибудь страну и переводят агрессию в нужное направление. Природная агрессия - источник насилия, выплеск которой необходим субъекту, не умеющему справляться с агрессивными состояниями. Насилие - это своего рода производный феномен от агрессии. Подробно нами анализировалась природа агрессии и насилия в статье [2] как главные причины социальных девиаций, агрессия выражается по-разному у различных народов, индивидов в зависимости от психологического типа личности: интроверт или экстраверт. У интровертов агрессия направлена против себя, обращена внутрь и чаще всего заканчивается суицидом; у экстравертов она обращена против другого (чужого) и выражается бандитизмом, экстремизмом, терроризмом. Если подумать, то агрессия и насилие - это две стороны одной медали, и они являются природными основаниями социальной жизни. Другими словами, вся история человечества построена на насилии и индивидуальной, видовой, межвидовой агрессии, вплоть до XX в. На протяжении XX в. - века двух мировыХ войн, потрясших все человечество, - значительно расширились объем и содержание понятия «человечество», а с другой - значительно возросла цена отдельной человеческой жизни. Но вместе с тем и экспоненциально возросла техникотехнологическая мощь государств, т. е. числитель в приведенной ранее формуле не так стремительно возрос. Это свидетельствует о том, что разработка культурных регуляторов, совершенствование средств сублимации агрессии, рост информационной емкости интеллекта и виртуализация социальной жизни - это совокупность проблем, с которыми в ближайшем будущем человечеству необходимо справиться, иначе тенденция увеличения совокупной сложности системы по мере перехода биосферы в антропосферу (по А. П. Назаретяну) или ноосферу (по В. И. Вернадскому) углубит разрыв между экологической средой и человечеством. Кроме того, есть зависимость и от ухудшения экологической ситуации в мире, связанной с ростом цивилизационных технологических решений. Во многих исследованиях указывается, что развитие человечества, увеличение антропогенной нагрузки сопровождалось нарастающим вторжением в биосферу и ее угнетением, которое приводило к уничтожению и изменению ландшафтов, в по- 
следующем - разрушению социальной системы, к катастрофам социального уровня. Примеров приводится множество: бездумная охота опустошала экологические ниши; неумеренный выпас скота опустошал и оголял почвы, и города засыпались песком; неправильно организованное земледелие на степных почвах приводило к истощению почв. Австралийский историк Д. Кристиан пишет: «Деградация среды вследствие быстрых социальных изменений, например, истребление мегафауны в каменном веке, злоупотребление искусственным орошением в Месопотамии в третьем тысячелетии до н. э. или в государстве Майя немногим более тысячи лет назад - обычное явление человеческой истории» [3, p. 474 475].

На философском конгрессе в Пекине (2018 г.) подняли вопрос об объеме и содержании понятия «человечность», но это уже XXI в. Вернемся в XX в., т. к. он замечателен не только гуманитарными прорывами в преодолении детской смертности, многих смертельных болезней, которые уносили миллионы жизней, но и демографическим взрывом (население земного шара увеличилось до 7 млрд человек) и снижением функции естественного отбора, служившего регулятором численности народонаселения земного шара. Зависимость численности индивидов внутри социальной группы (этнос, народ, народонаселение страны, человечество) от продовольствия, производимого ею, выражена реакционным законом Мальтуса. Но если заглянуть глубже в историю, то в великой китайской «Книге перемен» эта зависимость была выражена мудро: каждый человек должен уметь прокормить (добыть пищу) себя, свою семью, свой род и свой народ в конечном счете. И это идеал обычного человека, а не совершенномудрого правителя. Значит, никчемный человек не способен содержать семью, род, народ, поэтому трудолюбивый китайский народ увеличивает число граждан, может одеть, накормить весь земной шар. Излишки сельскохозяйственной продукции, дешевую продукцию легкой и электронной промышленности они продают во все страны мира. В основе идеала человека в Книге перемен лежит принцип «жень» - человеколюбие.

Лишь в середине XX в. плеяда выдающихся отечественных психологов, дидактов, методистов и других ученых разработали дидактические системы развивающего обучения, основанные не на просветлении (Будда Шакьямуни) или интуитивных догадках, или традиций (Аристотель, Платон, Сократ, Л. Н. Толстой и другие авторы моделей гуманистического образования), а на основе стройных психологических теорий (Л. С. Выготский, Д. Б. Эльконин, В. В. Давыдов, Л. В. Занков и другие). В Советском Союзе в 60-70 гг. ХХ в. Э. В. Ильенков, М. К. Мамардашвили, Ф. Т. Михайлов, Г. П. Щедровицкий и другие философы эксплицируют дидактические системы с точки зрения онтологии, гносеологии, философии науки и образования и создают философские концепции и теории, лежащие в основе систем развивающего образования. Вклад ученых и философов в создание системы гуманистического образования стал венцом идей гуманизма античности, эпохи Возрождения, эпохи Просвещения и конца XIX начала XX в. Это дар выдающихся умов ученых гуманистов. С другой стороны, гуманистическое образование неизбежно должно было выстроиться после двух 
Л. Г. Сандакова, Р. В. Ильин. Гуманизация образования в судьбе человечества: невозможность или дар XX века?

мировых войн и множества локальных «нефтяных» и «газовых» конфликтов. Как же человечество распорядилось этим гениальным духовным наследием XX в.?

В XXI в. эта система понимающего гуманистического, человекоразмерного образования, базовые идеи гуманизации образования трансформируются в «лжеучебный-лжевоспитательный конвейер» (по М. Н. Невзорову) [8]. Федеральные государственные стандарты разных номеров декларируют цели и задачи человекоразмерного образования, но образовательная практика такова, что до восьмидесяти процентов педагогических работников использует репродуктивные методы репрессивных систем образования (от монастырской системы до Я. А. Коменского, прусской системы обучения, применявшейся в царской армии и образовании, репродуктивной модели формирования строителя коммунизма Н. К. Крупской и др.). Воспитание в XXI в. становится приоритетным, т. к. история знает про людоедов-аристократов, про подростковую агрессию - травлю в социальных сетях, а также в реальности своих одноклассников, учителей. Потому что массовое образование построено по законам «механической солидарности» (Э. Дюркгейм), говорить о воспитании, в условиях страха и репрессий, не приходится. Педагогика и психология массовой школе чужда, большинство работников образования не знают тех высоких и пронизанных любовью к детям теориях и не желают знать. Профессия педагогического работника стала массовой, низкооплачиваемой и потерявшей былой статус. Феномен массового человека описан, а в современных условиях образовательная ситуация усложняется, образ дистанционного образования печален. Есть ли выход? Сможем мы воспользоваться даром выдающихся психологов, философов и педагогов XX в. или же будем способствовать упадку в образовании, в культуре и других сферах духовной жизни общества? Как отмечает М. Н. Невзоров [7], в педагогике известен «принцип выращивания» О. Анисимова, сущность педагогического проектирования, в котором осуществляется экзистенциальное пробуждение «человеческого в Человеке» в массовом педработнике, возрождение в образовательной организации педагогической концептосферы, в образование входит методология педагогического проектирования (его этапы), разработка проекта собственной педагогической деятельности как практики педагогической (педагога, организации, муниципалитета, территории). В образовательной организации зарождаются «органическая солидарность» (Э. Дюркгейм), педагогическое и детское коллективное сознание, как продукт проектирования - коллективный субъект развития, устремленный в будущее.

Между гуманистической и репрессивной традициями существует «неснимаемое противоречие»: гуманистическая основана на добровольном, радостном познании научных фактов и нравственных ценностей; другая - на насилии, вызванном природной агрессией, еще не сублимированной, так как методы и средства ее сублимации нужно знать и уметь применять (образование, творчество, юмор. сарказм и т. д.), а дети, приходящие в школу, еще ничего этого не знают, впрочем, как и студенты вузов, до изучения философии. В XXI в. остались, конечно, адепты развивающего, понимающего образования, в которой было диалектическое разрешение этого извечного конфликта. Они предлагают свои теории, парадигмы, модели. Например, дальневосточный ученый М. Н. Невзоров [7] 
предлагает матрицу «индивидуальности» (Р-Д-Д-Р) и схему педагогического процесса: внутренняя сторона процесса - динамика новообразований школьника по годам пребывания в школе, внешняя сторона педагогического процесса организация и мониторинг образовательного процесса.

\section{Лumepamypa}

1. Назаретян А. П. Нелинейное будущее. Мегаистория, синергетика, культурная антропология и психология в глобальном прогнозировании: монография. М.: АРГАМАКМЕДИА, 2017. $512 \mathrm{c}$.

2. Сандакова Л. Г. Философский анализ проблем суицида в Республике Бурятия // Актуальные проблемы социальной философии 2013. Вып. 2. С. 171-178.

3. Christian D. Maps of time: An introduction to Big History. Berkeley: Calif.: Univ.of California Press, 2004. $122 \mathrm{c}$.

4. Назаретян А. П. Антропология насилия и культура самоорганизации. Очерки по эволюционно-исторической психологии. М.: УРСС, 2008. 150-170.

5. Назаретян А. П. Виртуализация социального насилия: знамение эпохи? // Историческая психология и социология истории. 2009. Т. 2, № 2. С. 150-170.

6. Невзоров М. Н. Воспитание в ХХІ в.: миф или реальность // Воспитание в современном мире: новые контексты - новые решения: материалы V Междунар. науч.-практ. конф. (Хабаровск, 29-30 октября 2019 г.). Хабаровск: Изд-во Дальневост. гос. мед. ун-та, 2019. C. $185-197$.

7. Невзоров М. Н. Практика педагогическая: радостная и продуктивная жизнь взрослых и детей в образовании. Владивосток, 2019. 160 с.

8. Невзоров М. Н., Невзорова М. А. К вопросу об управлении гуманитарной системой образовательной организации: от лжеучебного-лжевоспитательного конвейера к человекоразмерному педагогическому процессу // Образование и педагог в условиях информационного социума: взгляд из будущего: материалы всерос. науч.-практ. конф. с междунар. участием / отв. ред. С. П. Машовец, Н. Б. Москвина. Уссурийск, 2017. C. $24-29$.

Статья поступила в редакиию 12.11.2020; одобрена после рецензирования 16.11.2020; принята к публикащчи 25.11.2020.

\section{HUMANIZATION OF EDUCATION IN THE FATE OF MANKIND: A FAILURE OR A GIFT OF THE $20^{\text {th }}$ CENTURY?}

Lyudmila G. Sandakova

Dr. Sci. (Philos.), A/Prof.,

Head of Department for Organizing Research Activities,

Altai State Institute of Culture

277 im. A. Yurina St., Barnaul 656055, Russia

aivt@list.ru

Roman V. Ilyin

Research Assistant,

Altai State Institute of Culture

277 im. A. Yurina St., Barnaul 656055, Russia

aivt@list.ru 
Abstract. The article analyzes the historical development of mankind, which, in our opinion, is a struggle between two principles - humanistic and technocratic, which originated in the Axial Age and continues to this day... In the $20^{\text {th }}$ century, the opposition between them was removed through the dialectical unity of external and internal; humanistic and technological. In the age we live in A. P. Nazaretyan resolved this contradiction by finding a relationship between them, and expressed it in the law of technical and humanitarian balance. Based on the corresponding model and the regulators introduced, he analyzes megatrends and mechanisms of evolution, projects a nonlinear future of mankind, striving for a balance between humanistic culture and human biological nature. We use A. P. Nazaretyan's model for the explication of humanistic education as a model of developmental education of the $20^{\text {th }}$ century, as a great gift of outstanding Soviet, Russian scientists. We consider that its introduction into the mass educational practice of modern education is inevitable.

Keywords: historical development; humanistic education; technocratic development of mankind; developmental teaching; humanization of education; law (model) of technical and humanitarian education; aggression; violence; megatrends; mechanisms of evolution; designing; educational practice; mass education; mass profession; humanistic culture and human biological nature. 